\title{
Hypertension and its correlates among in-school adolescents in Ekiti State, South-west, Nigeria
}

\author{
Eyitayo Ebenezer Emmanuel', Samuel Ayokunle Dada², Eyitope Oluseyi Amu³, \\ Victor Adovi Aduayi ${ }^{1}$, Oladele Ademola Atoyebi ${ }^{4}$, Oluwadare Marcus ${ }^{5}$, \\ Demilade Olusola Ibirongbe ${ }^{4}$
}

${ }^{1}$ Lecturer, ${ }^{3}$ Senior Lecturer, ${ }^{5}$ Senior Registrar, Department of Community Medicine, ${ }^{2}$ Senior Lecturer, Department of Medicine, Ekiti State University Teaching Hospital, Ado Ekiti, ${ }^{4}$ Senior Registrar, Department of Community Medicine, Federal Teaching Hospital, Ido Ekiti, Ekiti State, Nigeria

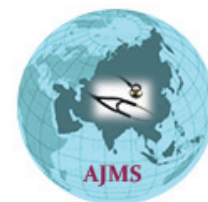

\section{A B S T R A C T}

Background: Hypertension is one of the major risk factors for cardiovascular disease (CVD). Though generally believed to be a disease of the adults, It has been shown to start in early life and tracks through adolescence into adulthood. Aims and Objectives: The objective of this study was to determine the prevalence of hypertension and associated factors among adolescents in Ekiti State. Materials and Methods: The study was a cross sectional survey involving 416 secondary school adolescents aged 10 to 19 years. A 'twostage' sampling technique was used to select the subjects. Facilitated self-administered questionnaire was used for the study. Data was analyzed using SPSS version 20. Level of significance was set at $P<0.05$. Results: A total of 416 students participated in the study. Prevalence of hypertension was $10.1 \%$ with male and female prevalence rates of $5.8 \%$ and $14.4 \%$ respectively $(P=0.004)$. Hypertension was higher among adolescents with $\mathrm{BMI} \geq$ the $85^{\text {th }}$ percentile for age and sex compared to those with lower BMI $(P=0.004)$. There was a weak positive correlation between $\mathrm{BMI}$ and blood pressure in the study (Systolic $r=0.33, P=0.001$ : diastolic $r=0.31, P=0.001$ ). Conclusion: The study concluded that hypertension is not a rare phenomenon among adolescents and that female gender and high BMI were the main risk factors for adolescent hypertension in this study.

Key words: Adolescents, Hypertension, Body mass index, Prevalence, Nigeria

\section{INTRODUCTION}

Hypertension is one of the major risk factors for cardiovascular disease (CVD). ${ }^{1}$ It is the most prevalent cardiovascular risk factor worldwide. ${ }^{2,3}$ It has been shown to be positively and progressively related to the risk of stroke and coronary heart disease and attributed to cause an estimated 7.5 million deaths globally. Though generally believed to be a disease of adulthood, hypertension has been shown to start in early life and tracks through adolescence into adulthood. ${ }^{4-6}$ In some age groups, the risk of CVD doubles for each incremental increase of $20 / 10 \mathrm{mmHg}$
Access this article online

Website:

http://nepjol.info/index.php/AJMS DOI: 10.3126/ajms.v8i4.17129

E-ISSN: 2091-0576

P-ISSN: 2467-9100 of blood pressure, starting as low as $115 / 75 \mathrm{mmHg}$. Hypertension in children and adolescents is defined as systolic blood pressure (SBP) and/or diastolic blood pressure (DBP), that is greater or equal to $95^{\text {th }}$ percentile for given age, gender and height on repeated (3 or more) measurements. ${ }^{8,9}$ The reference point of systolic/diastolic blood pressure $\geq 140 / 90 \mathrm{mmHg}$ is used for those above 17 years. ${ }^{10}$

A recent systematic review of studies done in the last 2 decades on the prevalence of hypertension in Nigeria, reported a crude prevalence range of $2.1 \%$ to 
$47.2 \%$ for hypertension in adults and 0.1 to $17.5 \%$ for hypertension in children and adolescents. ${ }^{4,11}$ In most studies, prevalence of hypertension was higher in males than females, similarly, the prevalence was higher in urban than rural areas. ${ }^{11}$ Studies have shown that the earlier the age of onset of hypertension, the more likely that the affected individual will develop complications if not well treated. ${ }^{4,12}$ Hence, early detection of hypertension and prompt intervention will ultimately lead to reduction of morbidity and mortality associated with long standing hypertension. Hypertension is often not detected among the adolescents as they are usually considered healthy and rarely visit hospital for medical check-up, and when they do, their blood pressure is hardly checked. This age group also suffered neglect by the erroneous assumptions of the health practitioners that adolescents are not likely to be hypertensive coupled with non-availability of cuffs of appropriate sizes for pediatrics blood pressure measurements in most cases. ${ }^{13}$

Hypertension has been shown to be associated with the some lifestyle related risk factors such as: smoking, alcohol intake, physical inactivity, obesity, and poor nutrition. The contribution of these risk factors usually start early in childhood and adolescence period. ${ }^{4,14}$ These risk factors are usually difficult to change once started early in life, hence the need to prevent the development of these risk factors through primordial prevention for effective control of adolescent hypertension and cardiovascular disease later in life. ${ }^{15,16}$ The more the combination of these risk factors in adolescents the worse the atherosclerotic changes in the walls of the blood vessels, hence the higher the chances of developing overt CVD. ${ }^{17}$

The study was designed to determine the prevalence of hypertension among secondary school adolescents in Ekiti State and also to identify some of the determinants of adolescent hypertension such as obesity, cigarette smoking and alcohol consumption among this age group.

\section{MATERIALS AND METHODS}

The study was a descriptive cross sectional study among in-school adolescents aged 10 to 19 years in Ekiti State. Four hundred and sixteen adolescents were recruited for the study from the public and private secondary schools in the state using a 'two-stage' sampling technique. In stage-1, four secondary schools were selected from the list of public and private secondary schools in the state by simple random sampling technique using the table of random numbers. While in stage-2, 52 consenting adolescents (26 boys \& 26 girls) were selected from each school. The respondents were adolescents between the ages of 10-19 years from selected schools in Ekiti State. Only those who assented to participate in addition to written parental consents were included in the study. Respondents who were absent from school during the period of the survey were excluded from the study.

Facilitated self-administered questionnaire was used for the study. Anthropometric measurements were taken by nurses and medical doctors. Height was measured using stadiometer, while weight was measured using electronic weighing scales Seca model. Weight was recorded in kilograms while height was recorded in metres. BMI was calculated by dividing the weight (in $\mathrm{Kg}$ ) by the square of the height (in metres). BMI greater than or equal to the $95^{\text {th }}$ percentile for age and sex was considered as obesity, while BMI between $85^{\text {th }}$ and less than $95^{\text {th }}$ percentile was regarded as overweight. ${ }^{18}$ Obesity and overweight were defined as body mass index greater than or equal to age specified international cut off points. ${ }^{19}$

Blood pressure (BP) of each subject was measured throughout the study with the same brand of an electronic sphygmomanometer (Omron $\left.{ }^{\circledR} \mathrm{HEM}-907\right)$ of appropriate cuff sizes in sitting position on the right arm after at least 5 minutes rest. Two consecutive measurements were obtained 5 minutes apart and the average of the two readings was obtained. Values were expressed in millimeter of mercury $(\mathrm{mmHg})$. The readings were further classified as hypertensive or not hypertensive using the $95^{\text {th }}$ percentile for age, sex and height.

\section{Operational definitions}

Participant were described as hypertensive if they were on any antihypertensive medication during the time of the survey, or if either or both the systolic and diastolic $\mathrm{BP}$ is/are greater than the $95^{\text {th }}$ percentile for age, sex and height. ${ }^{8,9}$

Respondents were classified as smokers (current daily and occasional smokers), or non-smokers. A smoker was defined as a person who, at the time of the survey, smokes any tobacco product either daily or occasionally. A non-smoker was classified as a person who never smoke. ${ }^{20}$

For alcohol intake, those with alcohol intake of more than 2 standard unit per day or intake of 5 or more standard units on any single occasion were regarded as at risk drinkers. ${ }^{21,22}$ Adolescents with significant alcohol intake were those that consume more than $16 \mathrm{~g}$ of alcohol per day or occasional intake of greater than or equal to $50 \mathrm{~g}$ of alcohol within few hours on any day. ${ }^{23}$

Data were analyzed with computerized statistical package for social sciences (IBM SPSS) version 20.0. 
Chi-square test was used to determine the association between hypertension and socio-demographic factors of respondents while Pearson's correlation was used to describe the strength of association between systolic/ diastolic blood pressure and the age and body mass index of the respondents. Significant $\mathrm{p}$-value was $P<0.05$. Ethical approval was obtained from the Research Ethics and Review Committee of the Federal Teaching Hospital, Ido-Ekiti (formerly Federal Medical Centre, Ido-Ekiti). Permission of the State Ministry of Education and the principals of the selected schools were also obtained. Written consent was obtained from students that are 18 and 19 year while for those less than 18 years, their assent was obtained in addition to written parental consent.

\section{RESULTS}

All the selected respondents (total of four hundred and sixteen consenting adolescents) participated in the study.

As shown in Table 1, the sex distribution of the respondents in the study was equal. The mean age of the study respondents was $14.8 \pm 2.2$ years, while the mean height and weight were $1.5 \pm 0.2 \mathrm{~m}$ and $43.6 \pm 10.1 \mathrm{Kg}$ respectively. Respondents mean systolic blood pressure was $108.0 \pm 14.7 \mathrm{mmHg}$, while the mean diastolic blood pressure of the respondents was $60.6 \pm 9.5 \mathrm{mmHg}$. About $6.7 \%$ of the respondents had BMI greater than or equal to the $85^{\text {th }}$ percentile for age and sex.

\begin{tabular}{|c|c|c|}
\hline Variables & Mean $\pm S D$ & Frequency $(\%)$ \\
\hline \multicolumn{3}{|l|}{ Demographics } \\
\hline Age (years) & $14.8 \pm 2.2$ & \\
\hline Height (M) & $1.5 \pm 0.2$ & \\
\hline Weight (Kg) & $43.6 \pm 10.1$ & \\
\hline Systolic Bp (mmHg) & $108.0 \pm 14.7$ & \\
\hline Diastolic Bp (mmHg) & $60.6 \pm 9.5$ & \\
\hline \multicolumn{3}{|l|}{ Gender } \\
\hline Male & & $208(50.0)$ \\
\hline Female & & $208(50.0)$ \\
\hline \multicolumn{3}{|l|}{ BMI percentile for age and sex } \\
\hline$<85^{\text {th }}$ & & $388(93.3)$ \\
\hline$\geq 85^{\text {th }}$ & & $28(6.7)$ \\
\hline \multicolumn{3}{|l|}{ Bood pressure category } \\
\hline Non-Hypertensive & & $374(89.9)$ \\
\hline Hypertensive & & $42(10.1)$ \\
\hline Systolic hypertension only & & $39(9.4)$ \\
\hline Diastolic hypertension only & & $1(0.2)$ \\
\hline $\begin{array}{l}\text { Both systolic and diastolic } \\
\text { hypertension }\end{array}$ & & $2(0.5)$ \\
\hline \multicolumn{3}{|l|}{ Social attributes } \\
\hline Smokers & & $10(2.4)$ \\
\hline Risky alcohol use & & $16(3.8)$ \\
\hline
\end{tabular}

About $10.1 \%$ of the respondents were hypertensive using the age, sex and height percentile reference charts. Respondents with isolated systolic hypertension constituted about $9.4 \%$, only one $(0.2 \%)$ of the respondents had isolated diastolic hypertension while about $0.5 \%$ respondents had both systolic and diastolic hypertension. About $2.4 \%$ of the respondents were smokers while risky alcohol use was reported in about $3.8 \%$ of the respondents as shown in Table 1.

As illustrated in Table $2,11 \%$ of the respondents between the ages of 15-19 years had hypertension compared to about $9 \%$ seen in the younger age group (10-14 years), this finding was however not statistically significant $(P=0.453)$. There is a statistically significantly association between the gender of the respondent and raised blood pressure with the females being more likely to be hypertensive than the males $\left(\chi^{2}=8.581, P<0.003\right)$. Similarly, those with BMI greater than or equal to the $85^{\text {th }}$ percentile for age and sex (overweight and obese) had a significantly higher prevalence of hypertension $(28.6 \%)$ compared to those with lower BMI percentile $(8.8 \%), P=0.004$.

There is no significant association between smoking and hypertension $(P=1.000)$. Although not statistically significant, those with risky alcohol intake were more likely to be hypertensive compared to the non-risk group $(P=0.212)$.

As shown in Table 3, there was a significant positive correlation between the respondents' body mass index and both the systolic and diastolic blood pressure $(\mathrm{r}=0.033$, $P<0.001$ and $\mathrm{r}=0.31, P<0.001$ respectively).

\section{DISCUSSIONS}

The prevalence of hypertension in the study population was $10.1 \%$ with male and female prevalence rates of $5.8 \%$ and $14.4 \%$ respectively. This gender difference in the observed prevalence of hypertension may probably be due to a greater delay in boys in completing pubertal development and attaining final height than in females and is similar to a recent report by Ujunwa et al in Enugu Southern Nigeria in 2013. ${ }^{4}$ The observed prevalence rate of $10.1 \%$ is also in agreement with that reported by Ejike et $\mathrm{al}^{24}$ in a neighboring state (Kogi State) but higher than the prevalence rate of hypertension obtained in some other studies. ${ }^{25,26}$ The difference in prevalence rates may be due to differences in the methodologies, and criteria for diagnosis of hypertension and regional variations. However, the observed prevalence rate falls within the documented prevalence rate of adolescent hypertension of 0.1 to $17.5 \%$ in Nigerian adolescents. ${ }^{411,2426}$ 


\begin{tabular}{|c|c|c|c|c|c|}
\hline \multirow[t]{2}{*}{ Variables } & \multicolumn{2}{|c|}{ Frequency (\%) } & \multirow[t]{2}{*}{$\mathbf{n}$} & \multirow[t]{2}{*}{$\chi^{2}$-Statistics ${ }^{a}(\mathrm{df})$} & \multirow[t]{2}{*}{$P$ value } \\
\hline & Normotensive & Hypertensive & & & \\
\hline \multicolumn{6}{|l|}{ Age group } \\
\hline 10-14 years & $192(91.0)$ & $19(9.0)$ & 211 & $0.562(1)$ & 0.453 \\
\hline $15-19$ years & $182(88.8)$ & $23(11.2)$ & 205 & & \\
\hline \multicolumn{6}{|l|}{ Gender } \\
\hline Male & $196(94.2)$ & $12(5.8)$ & 208 & $8.581(1)$ & 0.003 \\
\hline Female & $178(85.6)$ & $30(14.4)$ & 208 & & \\
\hline \multicolumn{6}{|l|}{ Smoking } \\
\hline Non-smoker & 365 (89.9) & $41(10.1)$ & 406 & $0.000(1)$ & 1.000 \\
\hline Smoker & $9(90.0)$ & $1(10.0)$ & 10 & & \\
\hline \multicolumn{6}{|l|}{ Alcohol intake } \\
\hline Not at risk & $361(90.2)$ & $39(9.8)$ & 400 & $1.373(1)$ & 0.212 \\
\hline At risk & $13(81.2)$ & $3(18.8)$ & 16 & & \\
\hline \multicolumn{6}{|c|}{ BMI percentile for age and sex } \\
\hline$<85^{\text {th }}$ & $354(91.2 \%)$ & $34(8.8 \%)$ & 388 & $11.289(1)$ & $0.004^{f}$ \\
\hline$\geq 85^{\text {th }}$ & $20(71.4 \%)$ & $8(28.6 \%)$ & 28 & & \\
\hline
\end{tabular}

$=$ Chi-square test for independence, $\mathrm{df}=$ degree of freedom, ${ }^{\mathrm{f}}=$ Fisher's exact

\begin{tabular}{|c|c|c|c|c|}
\hline \multicolumn{5}{|c|}{ Pearson's correlation } \\
\hline Variables & BMI & SBP & DBP & AGE \\
\hline $\mathrm{BMI}\left(\mathrm{Kg} / \mathrm{m}^{2}\right)$ & $2.7^{\mathrm{a}}$ & $<0.001^{\mathrm{b}}$ & $<0.001^{b}$ & $0.349^{b}$ \\
\hline $\mathrm{SBP}(\mathrm{mmHg})$ & $0.33^{c}$ & $14.7^{\mathrm{a}}$ & $<0.001^{\mathrm{b}}$ & $0.565^{\mathrm{b}}$ \\
\hline $\mathrm{DBP}(\mathrm{mmHg})$ & $0.31^{c}$ & $0.57^{c}$ & $9.5^{\mathrm{a}}$ & $0.134^{b}$ \\
\hline AGE (years) & $-0.05^{c}$ & $0.03^{c}$ & $0.07^{c}$ & $2.2^{\mathrm{a}}$ \\
\hline
\end{tabular}

Similar gender difference in the Blood pressure pattern has been documented with both the mean SBP and DBP being significantly higher in females than in males especially during the early and mid-adolescent stages., ${ }^{4,27}$ This gender difference in blood pressure pattern may also be attributed to hormonal changes that occur during puberty which has been noted to occur more rapidly in females than in males. ${ }^{9,28}$

Adolescent hypertension was not significantly associated with smoking and risky alcohol intake in this study. This may be due to the quantity consumed and duration of consumption which is usually longer in adult population compared to adolescent population. ${ }^{4}$ The danger in this however is that, it is possible that these young smokers and risky alcohol drinkers may continue up to adulthood thereby predisposing them to the long term effects of these risk factors. ${ }^{4,29,30}$

In addition, the study also revealed that adolescents who were either overweight or obese (those who had BMI greater than or equal to the $85^{\text {th }}$ percentile for age and sex) had significantly higher prevalence of hypertension. Similarly, the study revealed a positive correlation between BMI and the systolic and diastolic blood pressure of the respondents $(\mathrm{r}=0.033, P<0.001$ and $\mathrm{r}=0.31, P<0.001$ respectively). The coefficient of determination was about 0.11 and 0.1 for systolic and diastolic blood pressure respectively: meaning that $11 \%$ of the variations in systolic blood pressure could be explained by changes in BMI alone, while about $10 \%$ of the changes in the diastolic blood pressure could be explained by changes in BMI alone. These association between BMI and blood pressure is similar to the findings of Ogboye ${ }^{9}$ in her study in Lagos which revealed that blood pressure of adolescents tend to increase with increasing body mass index. Hence, a decrease in BMI could result in a lowering of both the systolic and diastolic blood pressure.

The implication of this study is that, hypertension exist in adolescents and that routine screening of adolescents for hypertension and overweight/obesity may assist in early detection and prevent worsening of the condition in adults. It may also reduce the prevalence of hypertension in adults, through early diagnosis and treatment.

\section{CONCLUSION}

This study revealed a relatively high prevalence rate of hypertension among adolescents studied and identified female gender and increasing BMI as associated risk factors in this group.

\section{Limitations of the study}

None inclusion of out of school adolescents may affect the external validity of the study. Other potential correlates of hypertension like levels of salt intake, physical activity levels and biochemical parameters were not assessed in the study.

\section{ACKNOWLEDGEMENT}

All the community health extension workers that assisted in data collection 


\section{REFERENCES}

1. Prabhjot A, Kaur N, Kumar $\mathrm{K}$ and Sighu $\mathrm{S}$. Variation in blood pressure among school children in Amristar (Punjab). Anthropologist 2005;7:201-204.

2. World Health Organization. The world health report 2002: reducing risks, promoting healthy life [Internet]. World Health Organization; 2002. Available from: http://www.who.int/ whr/2002/en/. Accessed 20//08/2015.

3. Lurbe E, Torro I, Alvarez V, Nawort T, Paya R, Redon J, et al. Prevalence of persistence, and clinical significance of masked hypertension in youth. Hypertension 2005;45:493-498.

4. Ujunwa FA, Ikefuna AN, Nwokocha ARC and Chinawa JM. Hypertension and prehypertension among adolescents in secondary schools in Enugu, South East Nigeria. Ital J Pediatr [Internet]. 2013/11/05. 2013;39(1):70. Available from: http:// www.ijponline.net/content/39/1/70. Accessed 20//08/2015.

5. Ejike C, Chukwu C, Ugwu C and Chukwu C. Hyperbolic Relationship between blood pressure and body mass index in a Nigerian Adolescent Population. Webmed Cent Hypertens. 2010;1(10):WMC00797.

6. Gidding SS and Samuel G. Cardiovascular risk factors in adolescents. Curr Treat Options Cardiovasc Med 2006;8(4):269-275.

7. Finucane MM. Stevens GA, Cowan MJ, Danaei G, Lin JK, Paciorek CJ, et al. National, regional, and global trends in bodymass index since 1980: systematic analysis of health examination surveys and epidemiological studies with 960 country-years and 9.1 million participa. Lancet 2011; 377:557-567.

8. NIH. The Fourth Report on the Diagnosis, Evaluation, and Treatment of High Blood Pressure in Children and Adolescents. Natl Institutes Heal. 2005;05-5267:1-60.

9. Ogboye O. Blood pressure and its correlates in children and adolescents in urban Nigeria [Internet]. University of Warwick; 2012. Available from: http://wrap.warwick.ac.uk/56120/1/ WRAP_THESIS_Ogboye_2012.pdf. Accessed 22//08/2015.

10. Giles TD, Materson BJ, Cohn JN and Kostis JB. Definition and classification of hypertension: an update. J Clin Hypertens 2009;11(11):611-614.

11. Akinlua JT, Meakin R, Umar AM and Freemantle N. Current prevalence pattern of hypertension in Nigeria: A systematic review. PLoS One 2015;10(10).

12. Franco $\mathrm{OH}$, Peeters $\mathrm{A}$, Bonneux $\mathrm{L}$, De Laet $\mathrm{C}$, Peters $\mathrm{A}$, Bonneux L, et al. Blood pressure in adulthood and life expectancy with cardiovascular disease in men and women. Hypertension 2005; 46(2):280-286.

13. Ejike CECC, Ugwu CE and Ezeanyika LUS. Variations in the prevalence of point (pre)hypertension in a Nigerian school-going adolescent population living in a semi-urban and an urban area. BMC Pediatr [Internet] 2010;10(1):13. Available from: http:// dx.doi.org/10.1186/1471-2431-10-13. Accessed 22//08/2015.
14. Perez MK and Nield LS. When to consider surgery for an obese teen. Consult Pediatr 2009;8:428-431.

15. Hamidu LJ, Okoro EO and Ali MA. Blood pressure profile of Nigerian children. East Afr Med J 2000;77:180-184.

16. Cole TJ, Bellizzi MC, Flegal KM and Dietz WH. Establishing a standard definition for child overweight and obesity worldwide: international survey. BMJ 2000;320(7244):1240.

17. May AL, Kuklina E V and Yoon PW. Prevalence of cardiovascular disease risk factors among US adolescents, 1999-2008. Pediatrics 2012;129(6):1035-1041.

18. Daniels SR, Arnett DK, Eckel RH, Gidding SS, Hayman LL, Kumanyika S, et al. Overweight in children and adolescents pathophysiology, consequences, prevention, and treatment. Circulation 2005;111(15):1999-2012.

19. Cole TJ, Flegal KM, Nicholls $D$ and Jackson AA. Body mass index cut-offs to define thinness in children and adolescents. International Survey. BMJ 2007;335:194.

20. World Health Organization. Guidelines for controlling and monitoring the tobacco epidemic. 1998;

21. World Health Organization. Global status report on alcohol and health-2014. 2014;

22. Shahwan-Akl L. Prevalence of cardiovascular risk factors among Australian-Lebanese in Melbourne. Victoria University; 2001.

23. Thompson W, Lande RG, Kalapatapu RK. Alcoholism: Available from: http://emedicine.medscape.com/article/285913. Accessed 20//08/2015

24. Ejike CECC, Ugwu CE, Ezeanyika LUS, Olayemi AT, Ejike EC, Ugwu CE, et al. Blood pressure patterns in relation to geographic area of residence: a cross-sectional study of adolescents in Kogi state, Nigeria. BMC Public Health [Internet]. 2008/12/18. 2008;8(1):411. Available from: http://dx.doi. org/10.1186/1471-2458-8-411. Accessed 20//08/2015.

25. Akinkugbe FM, Akinwolere $\mathrm{AO}$ and Kayode $\mathrm{CM}$. Blood pressure in Nigerian adolescents. West Afr J Med 1999;18.

26. Mijinyawa MS, Iliyasu Z, Borodo MM, Illiyasu Z, Borodo MM, Iliyasu Z, et al. Prevalence of hypertension among teenage students in Kano, Nigeria. Niger J Med 2008; 17(2):173-178.

27. Jaddou HY, Bateiha AM, Khawaldeh AM, Goussous YM and Ajlouni KM. Blood pressure profile in school children and adolescents in Jordan. Ann Saudi Med. 2001; 21:123-126.

28. Monyeki KD and Kemper HCG. Risk factors for elevated blood pressure and how to address cardiovascular risk factors. A review in pediatrics population. Hum Hypertens 2008; 22:450-459.

29. Salawu F, Danburam A, Isa B and Agbo J. Cigarette smoking habits among adolescents in Northeast Nigeria. Internet $\mathrm{J}$ Epidemiol 2010;8(1):1.

30. Igwe WC, Ojinnaka N, Ejiofor SO, Emechebe GO and Ibe BC. Socio-demographic correlates of psychoactive substance abuse among secondary school students in Enugu Nigeria. Eur J Soc Sci 2009; 12:277-283.

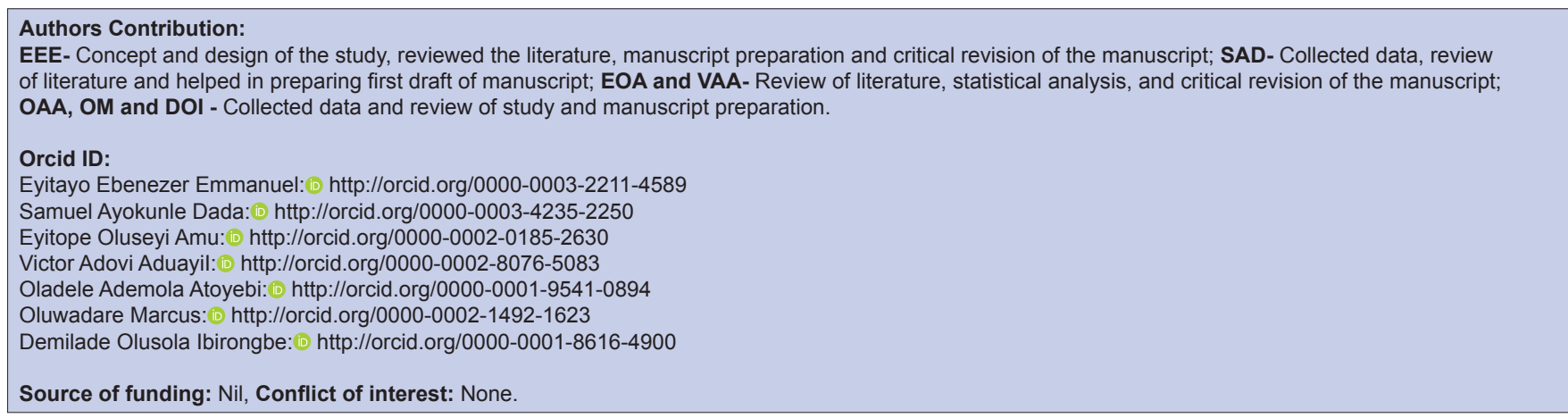

